\title{
ANÁLISE MORFOMÉTRICA DA BACIA HIDROGRÁFICA DO RIO JUCU-ES E ESPACIALIZAÇÃO DA PRECIPITAÇÃO MÉDIA ANUAL PELO MÉTODO IDW
}

Mariana Carneiro Viana - marianacviana@outlook.com Universidade Estadual do Sudoeste da Bahia

Grasielly Gusmão Rocha - grasiellygusmao@gmail.com

Universidade Estadual do Sudoeste da Bahia

Victor Hugo Morais Silva - eng.vhms@ hotmail.com

Universidade Estadual do Sudoeste da Bahia

Alison Silva dos Santos - alisonss@ outlook.com

Universidade Estadual do Sudoeste da Bahia 


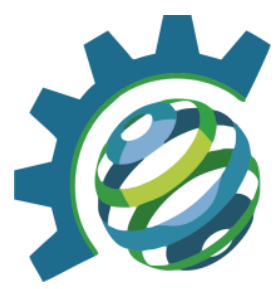

\section{RESUMO}

O presente estudo objetivou obter as características morfométricas da bacia hidrográfica do rio Jucu, localizada no estado do Espírito Santo, utilizando dados através da Shuttle Radar Topography Mission (SRTM), em ambiente de Sistema de Informações Geográficas (SIG). De posse do Modelo Digital de Elevação (MDE) e da delimitação da bacia, foram obtidos diferentes aspectos morfométricos e a precipitação média. A área de drenagem encontrada foi de $2.056,50 \mathrm{~km}^{2}$ e o perímetro de $351,92 \mathrm{~km}$. A bacia do Rio Jucu apresentou coeficiente de compacidade de 2,17, comprimento do rio principal 146,13 km e comprimento total dos cursos d'água $1.605,72 \mathrm{~km}$. As densidades de drenagem e de confluência obtidas foram de 0,78 e $0,36 \mathrm{~km} / \mathrm{km}^{2}$, respectivamente. A declividade média da bacia foi de $32 \%$. Após a análise dos resultados alcançados, concluiu-se que a bacia possui formato irregular, densidade de drenagem regular e baixa susceptibilidade a enchentes em condições normais de precipitação. As técnicas de geoprocessamento aplicadas e os dados SRTM utilizados se mostraram eficientes na obtenção das características morfométricas, sendo os resultados obtidos de forma rápida e confiável.

Palavras-chave: hidrologia, lâmina precipitada, sistema de informação geográfica.

\section{INTRODUÇÃO/OBJETIVO}

Uma bacia hidrográfica pode ser definida como uma unidade captadora de água da chuva e uma unidade de planejamento e gerenciamento ambiental, que possibilita avaliar as atividades antrópicas e suas alterações no ambiente e no equilíbrio hidrológico (CARVALHO, 2010).

Para realização de um diagnóstico ambiental local e regional, a caracterização morfométrica de uma bacia hidrográfica é uma das principais metodologias executadas e tem como objetivo esclarecer o entendimento da dinâmica ambiental local e regional. As configurações geométricas de uma bacia permitem concluir sobre os sistemas ambientais, sendo relacionado ao arranjo estrutural e à influência mútua entre as vertentes e a rede de canais fluviais (CHRISTOFOLETTI, 1999 apud MACHADO et al, 2011).

A análise morfométrica corresponde a um conjunto de procedimentos que caracterizam aspectos geométricos e de composição dos sistemas ambientais, servindo como indicadores relacionados à forma, ao arranjo estrutural e a interação entre os aspectos e a rede de canais fluviais de uma bacia hidrográfica (CHRISTOFOLETTI, 1999), que por sua vez evidenciam situações e valores que extrapolam as questões hidrológicas e geomorfológicas.

Atualmente, com a evolução dos Sistemas de Informação Geográfica (SIGs), que englobam uma combinação de tecnologias que vão desde o sensoriamento remoto e geoprocessamento aos Modelos Digitais de Elevação (MDE), tem sido permitido mapeamentos e caracterizações com consideráveis índices de confiabilidade e precisão (GUEDES E SILVA, 2012). Os SIGs possibilitam a espacialização de dados obtidos pontualmente sobre a superfície terrestre e a realização de diversas análises espaciais de dados, constituindo-se uma importante ferramenta no campo das geociências. (Druck, 2004).

Diante do exposto, o presente estudo objetivou determinar as características morfométricas e a precipitação média da bacia hidrográfica do rio Jucu, que é uma fonte hídrica imprescindível para a população da região metropolitana da grande Vitória. 

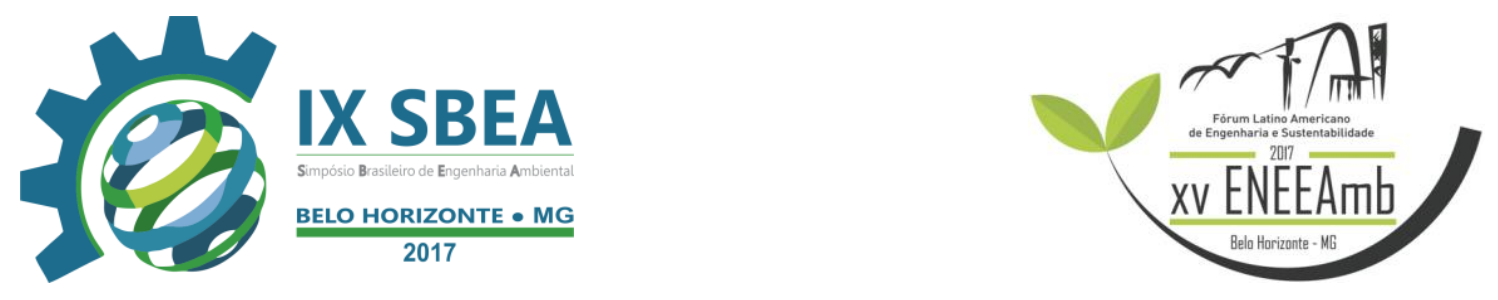

\section{METODOLOGIA}

\subsection{Caracterização da área de estudo}

O local do presente estudo é o Rio Jucu, pertencente à bacia hidrográfica 5 , do Atlântico Leste. Neste rio, considerando o sistema de projeção Universal Transversa de Mercator (UTM), está contido na zona 24S, entre os paralelos N: 7770611 - 7724726 e meridianos E: 276767 - 360808, sendo inteiramente situado no estado do Espírito Santo. Apresenta características adequadas para seu enquadramento dentro da classe II, segundo resolução CONAMA 357/05.

O rio Jucu, possui ottocodificação 7714 , sendo sua nascente localizada no município de Domingos Martins, desembocando no oceano Atlântico, através da barra do Jucu. Ao longo da sua extensão, a bacia do rio Jucu abrange os municípios de Vila Velha, Viana, Cariacica, Marechal Floriano e Vitória (Figura 1).

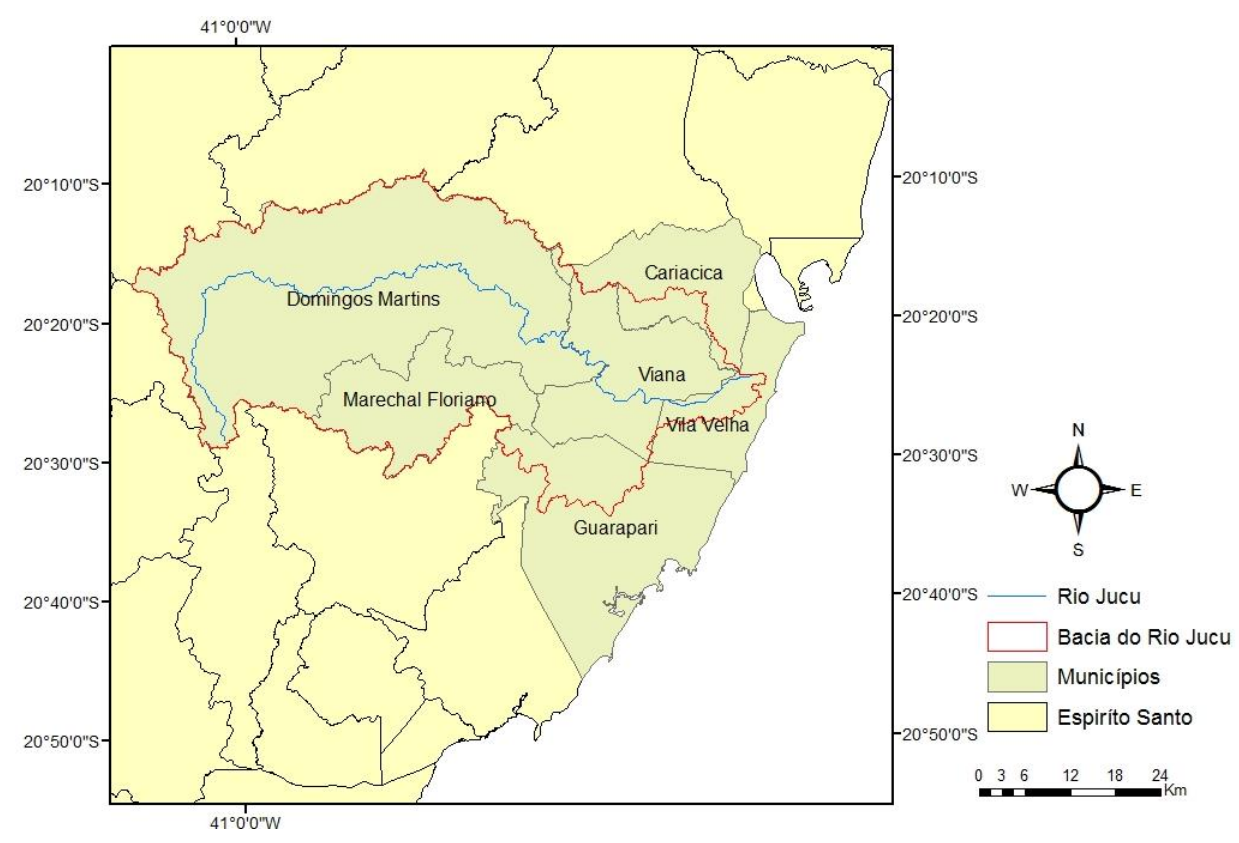

Figura 1: Municípios que integram à Bacia Hidrográfica do Rio Jucu.

A bacia hidrográfica do rio Jucu tem seus limites físicos com a baía de Vitória a leste, ao norte com a bacia do rio Santa Maria da Vitória, a sudoeste com a bacia do rio Itapemirim e ao sul com as bacias do rio Benevente e Guarapari.

Em relação ao clima, dois tipos climáticos predominam na bacia do rio Jucu, o tropical úmido de altitude, com temperaturas amenas no verão e intensas precipitações orográficas em vários períodos do ano e o tropical úmido das faixas litorâneas. Devido às chuvas orográficas, os índices pluviométricos da região serrana são mais elevados que os do litoral.

Na região serrana o Jucu apresenta dois braços: o braço sul, mais curto, com 67,43 Km de extensão e o braço norte, mais extenso, com 126,56 Km. Após a confluência de seus braços passa a ser chamado apenas de Jucu, em seguida percorre 42,94 $\mathrm{Km}$ até atingir sua foz, 


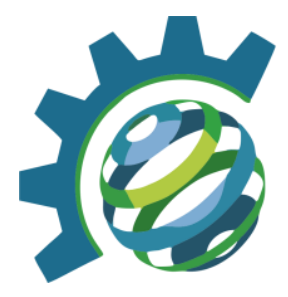

totalizando 169,5 Km de extensão. Entre seus principais afluentes estão os rios Barcelos, Ponte, Melgaço, Chapéu, Galo, Fundo, Jacarandá, Calçado e Claro.

\subsection{Processamento de Dados}

Para a geração do Modelo Digital de Elevação (MDE) foram utilizadas imagens SRTM (Shuttle Radar Topography Mission), disponibilizadas no portal do Earth Explorer (USGS, 2017), estas foram encontradas no formato GEOTIFF, com resolução espacial de 30 metros. As cartas de conexão utilizadas para abranger a área delimitada pela bacia foram: s21_w041 e s21_w042. Para a manipulação dessas imagens foi utilizado o software ArcGis 10/ArcMap do ESRI.

\subsection{Obtenção do MDEHC e delimitação da Bacia}

Inicialmente, para a obtenção das características morfométricas da bacia, foi utilizado MDE na geração do Modelo Digital de Elevação Hidrologicamente Consistente (MDEHC). As imagens SRTM possuíam um sistema de coordenadas geográficas datum WGS84, tornando imprescindível a conversão do sistema de projeção para UTM e Datum SIRGAS 2000, fuso $24 \mathrm{~S}$.

A geração do MDEHC iniciou-se pelo tratamento do MDE a partir da eliminação das depressões espúrias do arquivo, uma vez que não corrigidas podem influenciar no escoamento superficial. Nesse sentido, necessitou preencher as depressões e, após esse procedimento, determinar uma nova direção de escoamento por meio das ferramentas Fill e Flow Direction do software, respectivamente.

O acumulo do fluxo do MDE, ou seja, o escoamento acumulado, foi obtido pela função Flow Accumlation utilizando a direção do escoamento anterior como referência. Feito isso, seguiu-se a produzir uma drenagem numérica da bacia através do acumulo de 15000 células neste estudo. Deste modo, realizado todos esses procedimentos, pode-se considerar que o MDE está condicionado hidrologicamente para a determinação das variáveis morfométricas da bacia através do MDEHC obtido. Por fim, a delimitação da Bacia do Rio Jucu foi efetivada de maneira automática pelo ArcGis 10/ArcMap com auxílio do próprio MDEHC e da determinação do local da foz.

\subsection{Determinação dos parâmetros morfométricos}

Após a delimitação da bacia foram obtidas diversas características morfométricas: área da bacia $(\mathrm{A})$, perímetro da bacia $(\mathrm{P})$, coeficiente de compacidade $(\mathrm{Kc})$, comprimento do rio principal, comprimento total dos cursos d'água, densidade de drenagem (Dd), densidade de confluências (Dc), declividade média da bacia, declividade do rio principal.

$\mathrm{O}$ coeficiente de compacidade (Kc) relaciona a forma da bacia a um círculo, constituindo a relação entre o perímetro da bacia e a circunferência de um círculo de área igual a da bacia. Seu valor é superior a 1, quanto mais próximo o $\mathrm{Kc}$ for de 1 , mais suscetível a enchentes será a bacia. A determinação de Kc é baseada na equação (1).

$$
\mathrm{Kc}=0,28 \times \frac{\mathrm{P}}{\sqrt{A}}
$$



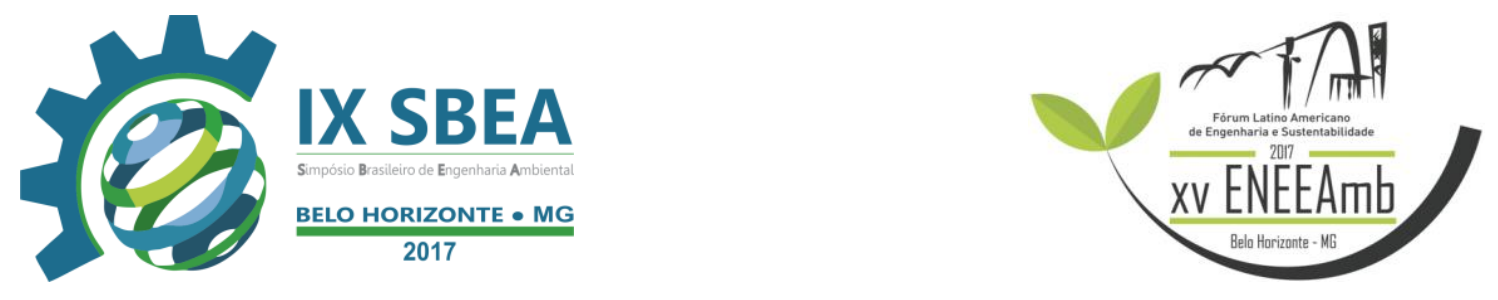

Sendo: $\mathrm{Kc}=$ coeficiente de compacidade, adimensional; $\mathrm{A}=$ área da bacia $\left(\mathrm{m}^{2}\right) ; \mathrm{P}=$ perímetro da bacia, (m).

Quanto ao índice de circularidade, pode-se considerar outra característica em que se relaciona a forma da bacia a de um círculo. $O$ índice de circularidade tende para 1 à medida que a bacia se aproxima da forma circular e diminui quando a bacia se torna alongada. Para efetuar o cálculo utiliza-se a equação (2), em que IC é o índice de circularidade, A a área de drenagem $\left(\mathrm{m}^{2}\right)$ e $\mathrm{P}$ o perímetro $(\mathrm{m})$.

$$
\mathrm{IC}=\frac{12,57 \mathrm{XA}}{\mathrm{P}^{2}}
$$

Quanto às altitudes e declividades médias, máximas e mínimas foram obtidas automaticamente através do MDEHC, utilizando a classificação da EMBRAPA (2009) para classificar as classes de declividade da bacia.

Já a densidade de drenagem apresenta a relação entre o somatório dos comprimentos de todos os rios e a área total da bacia. Seu estudo indica a maior ou menor velocidade com que a água deixa a bacia, fornecendo informações sobre a eficiência de drenagem da mesma. Para a determinação desse índice foi utilizada a equação (3), onde Dd é a densidade de drenagem $\left(\mathrm{km} \mathrm{km}^{-2}\right)$, Lt seria o comprimento de todos os rios $(\mathrm{km})$, A é a área de drenagem $\left(\mathrm{km}^{2}\right)$.

$$
\mathrm{Dd}=\frac{\mathrm{Lt}}{\mathrm{A}}
$$

A densidade de confluências é considerada uma forma mais simples de representar a densidade de drenagem de uma bacia e é obtida dividindo-se o número de confluências ou bifurcações apresentadas pela rede de drenagem pela área da bacia (Tucci, 1997). Para a determinação desse índice foi utilizada a equação (4), onde Dc é a densidade de confluência $\left(\mathrm{km} / \mathrm{km}^{2}\right)$, conf é o número de confluências e A é a área de drenagem $\left(\mathrm{km}^{2}\right)$.

$$
\mathrm{Dc}=\frac{\mathrm{conf}}{\mathrm{A}}
$$

\subsection{Determinação da precipitação média da bacia}

Para a obtenção dos dados de precipitação, foram escolhidas 13 estações pluviométricas que interagem dentro e nas proximidades da Bacia do Rio Jucu. Em seguida, fez-se necessário baixar os dados dessas estações, a partir das séries histórias disponíveis pela Agência Nacional das Águas (ANA, 2017). Neste estudo, foram utilizados os dados entre os anos de 1969 a 1999.

Inicialmente, criou-se uma planilha no Excel, no qual foram calculadas as médias de precipitação ocorridas ao longo dos 30 anos registrados de cada estação. Posteriormente, foi criada uma nova coluna para cada latitude e longitude das estações. Após esse procedimento, a lista de coordenadas foi importada para o ArcMap através da ferramenta Convert Coodirnate 
Notation. O processo resultou em um shapefile de pontos com novos dados na tabela de atributos, cada ponto corresponde a uma estação pluviométrica.

Para realizar a interpolação dos dados de precipitação, foi utilizado o método da Interpolação pela Ponderação do Inverso da Distância (IDW). Foi criada inicialmente uma máscara com o shapefile de polígono da área da bacia para definir o local onde será realizado o procedimento. Para isso, necessitou-se fazer as configurações do ambiente pelas ferramentas Environments/Processing Extent e Raster Analystsis, ambos selecionando a máscara da bacia. Em seguida, na criação do mapa da precipitação, iniciou-se a interpolação a partir da opção Interpolation/IDW dos pontos das médias das chuvas usando a resolução espacial do raster interpolado. Por fim, foi realizado o processo de isoietas do raster através da ferramenta Contour with Barriers.

\section{RESULTADOS E DISCUSSÃO}

As características morfométricas da bacia hidrográfica do Rio Jucu estão apresentadas na Tabela 1. De acordo com as análises realizadas, a bacia apresentou uma área de drenagem de $2056,50 \mathrm{~km}^{2}$ e perímetro igual a $351,92 \mathrm{~km}$.

Tabela 1. Características morfométricas da bacia hidrográfica do rio Jucu.

$$
\text { Características Morfométricas }
$$

\begin{tabular}{lr}
\hline Área $\left(\mathrm{km}^{2}\right)$ & 2056,5 \\
Perímetro $(\mathrm{km})$ & 351,92 \\
Coeficiente de compacidade $(\mathrm{Kc})$ & 2,17 \\
Índice de circularidade $(\mathrm{IC})$ & 0,21 \\
Comprimento do rio principal $(\mathrm{km})$ & 146,13 \\
Comprimento total dos cursos d'água $(\mathrm{km})$ & 1605,72 \\
Densidade de drenagem $\left(\mathrm{km} \mathrm{km}^{-2}\right)$ & 0,78 \\
Densidade de confluências $\left(1 / \mathrm{km}^{2}\right)$ & 0,36 \\
Declividade média da bacia $(\%)$ & 32 \\
\hline
\end{tabular}

Considerando os resultados obtidos para o coeficiente de compacidade $(2,17)$ e para índice de circularidade $(0,21)$, pode-se inferir que a bacia hidrográfica do rio Jucu é pouco susceptível a enchentes, em condições normais de precipitação. Para o índice, valores menores que 0,51 sugerem que a bacia possui um formato mais alongado, contribuindo para o processo de escoamento e desfavorecendo processos de inundação e picos de cheias (SCHUMM, 1956).

A densidade de drenagem foi considerada baixa, pois o valor encontrado foi de 0,78 $\mathrm{km} \mathrm{km}^{-2}$, menor que a classificação segundo Christofoletti (1974), que é de $5 \mathrm{~km} \mathrm{~km}^{-2}$. Isso indica que a área é permeável e de relevo plano e suave (OLIVEIRA et al, 2010), apresentando baixa relação entre o comprimento de rios e a área da bacia, denotando um eficiente escoamento de fluxo de água e boa infiltração para o lençol freático, isto é, uma menor propensão a inundações.

Por se tratar de uma forma mais simples de se representar a densidade de drenagem de uma bacia, a densidade de confluência não apresenta a mesma precisão, mas serve para se avaliar superficialmente a drenagem da bacia (BORSATO, 2004). Com isso, verifica-se que a bacia do rio Jucu apresenta o índice de 1 (uma) confluência para cada $0,36 \mathrm{~km}^{2}$ de área de bacia. 

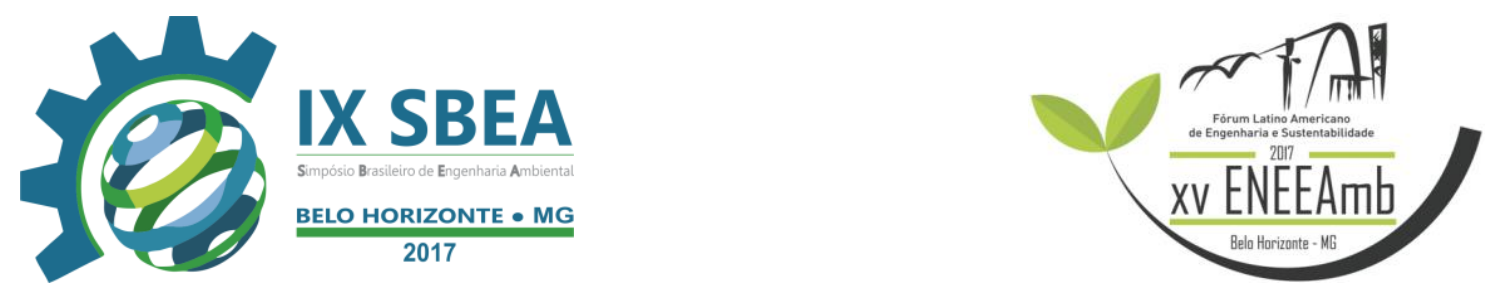

Em relação à declividade, observa-se que os relevos variam de plano a fortemente montanhoso (Figura 2). A bacia do rio Jucu apresentou uma declividade média de $32 \%$, que segundo a classificação da EMBRAPA (2009), caracteriza-se como relevo fortemente ondulado.

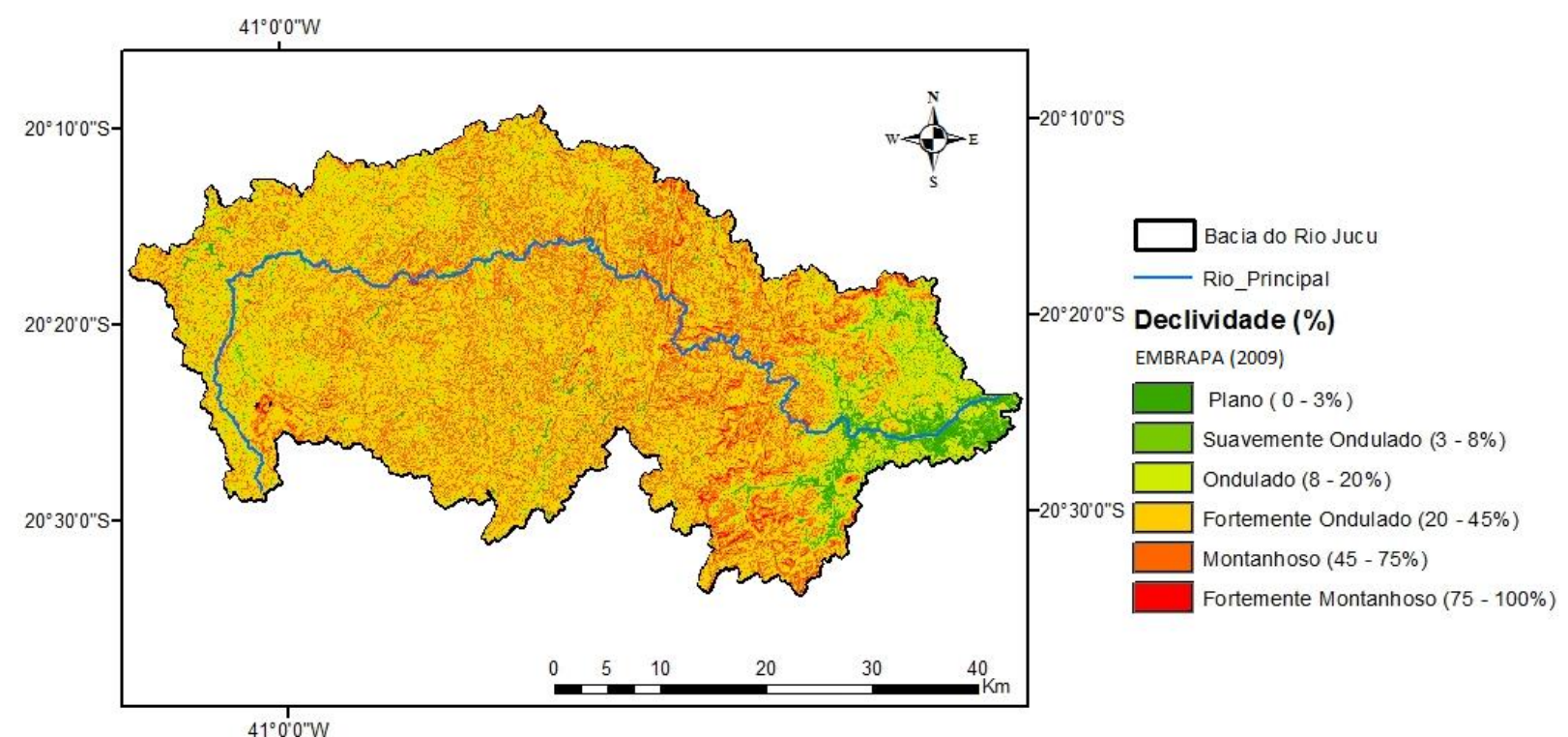

Figura 2. Distribuição espacial da declividade na Bacia Hidrográfica do Rio Jucu.

Os dados de precipitação e suas respectivas estações pluviométricas, dentro e nas proximidades da bacia, encontram-se na Tabela 2.

Tabela 2. Dados pluviométricos da bacia do rio Jucu, 1969 a 1999.

\begin{tabular}{ccc}
\hline Estação & Cidade & Média (Mm) \\
\hline Arace (DNOS) & Domingo Martins & 1344,22 \\
São Rafael & Domingos Martins & 1135,06 \\
Perobinha (DNOS) & Domingos Martins & 1270,02 \\
Córrego Do Galo & Domingos Martins & 1357,4 \\
Marechal Floriano (DNOS) & Domingos Martins & 1552,33 \\
Fazenda Jucuruaba & Viana & 1256,49 \\
Ponta Da Fruta & Vila Velha & 1110,63 \\
Duas Bocas (DNOS) & Cariacica & 1454,35 \\
Garrafão (DNOS) & Santa Leopoldina & 1293,91 \\
Conceição Do Castelo (DNOS) & Conceição Do Castelo & 1442,5 \\
Vila Nova Maravilha & Alfredo Chaves & 2179,88 \\
Matilde (DNOS) & Alfredo Chaves & 1745,68 \\
Guarapari (DNOS) & Guarapari & 1196,73 \\
\hline & & Média $=1410,71$
\end{tabular}

Média $=1410,71$ 


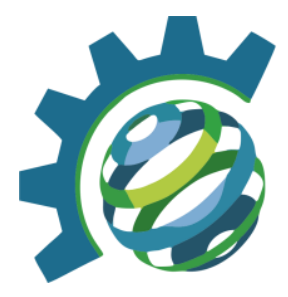

A precipitação média da bacia, no período de 1969 a 1999, foi de 1410,71 mm, sendo a estação de Vila Nova Maravilha, localizada no município de Alfredo Chaves a que apresentou os maiores índices pluviométricos, com um total precipitado de $2179,88 \mathrm{~mm}$. A estação com os índices mais baixos foi a de Ponta da Fruta, localizada em Vila Velha, com 1110,63 mm precipitados. Tais resultados não condizem com a realidade atual, pois a bacia do rio Jucu sofre um período de pouca chuva e apresenta índices pluviométricos abaixo da média histórica, segundo o Centro Capixaba de Meteorologia do Instituto Capixaba de Pesquisa, Assistência Técnica e Extensão Rural (INCAPER, 2014).

Analisando a espacialização dos dados da precipitação média anual dentro da bacia (figura 3), podemos verificar que a precipitação é quase homogênea em toda sua área.

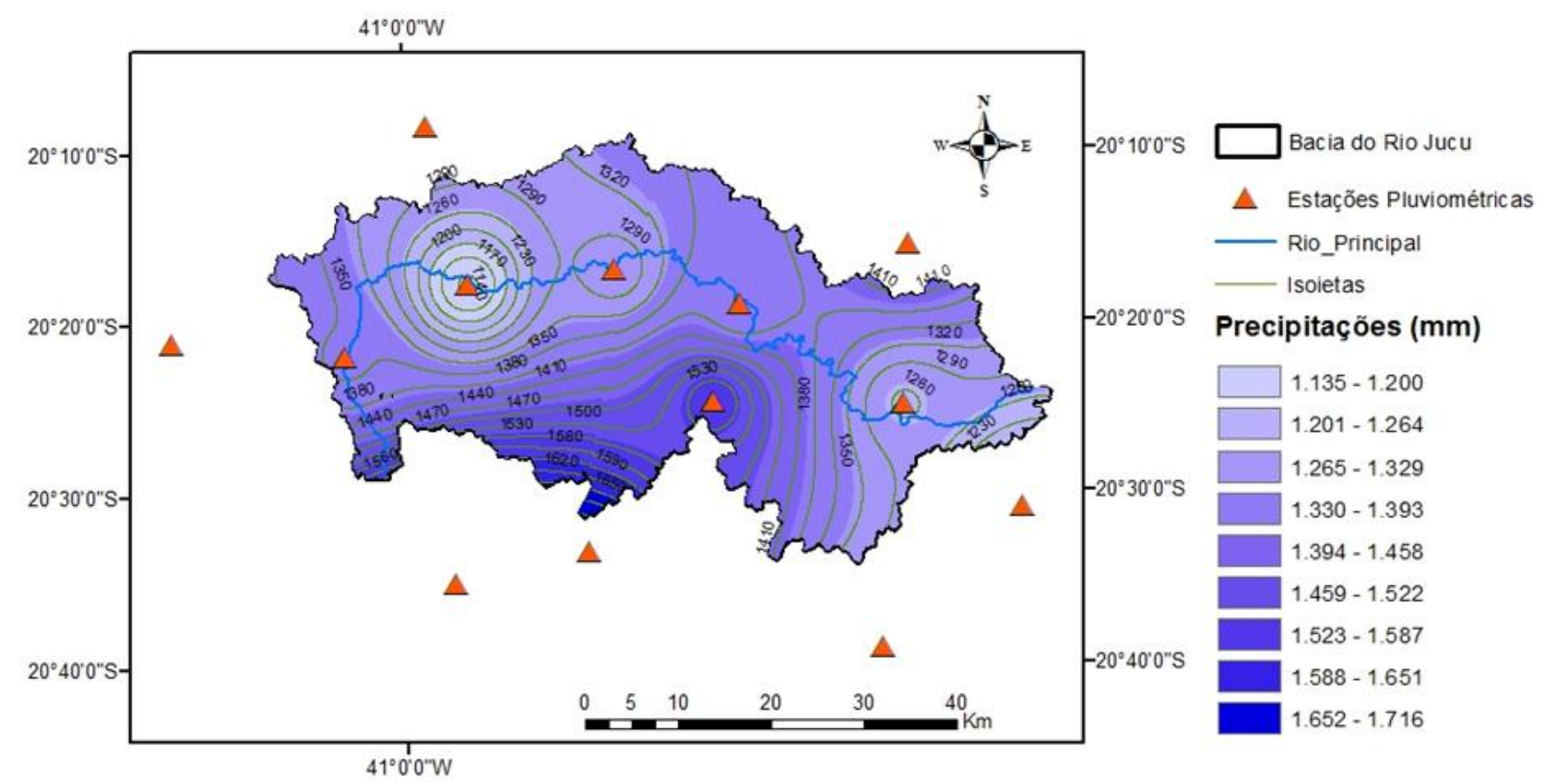

Figura 3. Mapa de Precipitação da Bacia do Rio Jucu, gerado pelo modelo IDW.

A elevada variabilidade das precipitações pluviais podem suceder ocasiões de secas e enchentes, que geram impactos negativos na produtividade de cultivos, desmoronamentos e dispersão de enfermidades ligadas a água. Desta maneira, é de ampla seriedade o entendimento da precipitação média, da dinâmica da água no solo e do balanço hídrico da bacia hidrográfica como integração de gestão (SWAROWSKY et al., 2010).

\section{CONCLUSÕES/RECOMENDAÇÕES}

Diante desses resultados, concluiu-se que a bacia hidrográfica do rio Jucu possui formato irregular, alongado e, dessa forma, a bacia não está sujeita a grandes enchentes, o que pode ser evidenciado pelo coeficiente de compacidade maior que $1,50(\mathrm{Kc}=2,17)$. A bacia apresentou uma baixa densidade de drenagem, $0,78 \mathrm{~km} / \mathrm{km}^{2}$, isto pode ocorrer devido a capacidade de infiltração da água no solo. A bacia apresenta relevo fortemente ondulado, com 

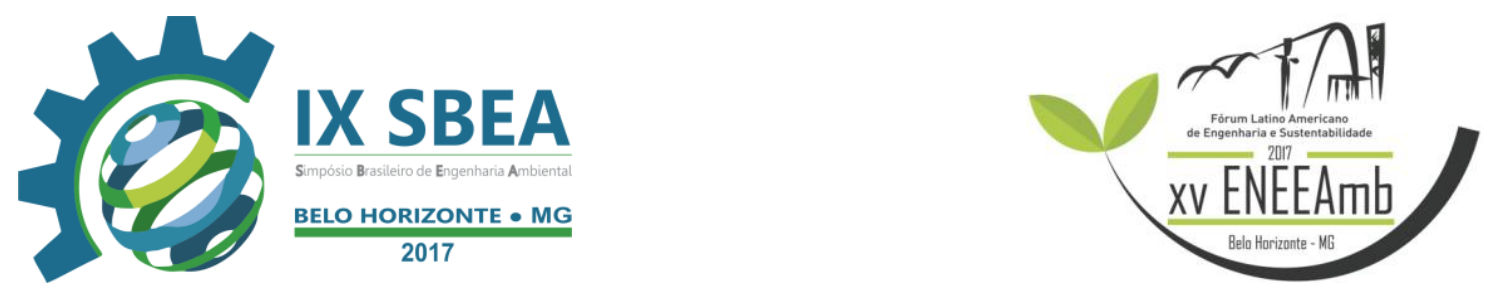

$32 \%$ de declividade, o que pode ser determinante no tempo de concentração da água na bacia, através do aumento da velocidade de escoamento.

\section{REFERÊNCIAS BIBLIOGRÁFICAS}

ANA - Agência Nacional de Águas. Series históricas de estações pluviométricas gratuitas. Acesso em 17 de abril de 2017. Disponível em <http://hidroweb.ana.gov.br/>

BORSATO, F. H.; Martoni, A. M. Estudo da fisiografia das bacias hidrográficas urbanas no Município de Maringá, Estado do Paraná. Acta Scientiarum. Human and Social Sciences, Maringá, v. 26, n. 2, p. 273-285, 2004.

CARVAlho, P. R. S.; GUimarães, R. F.; CARVAlHo JÚNiOR, O. A. Análise comparativa de métodos para delimitação automática das sub-Bacias do alto curso do Rio Preto. Espaço \& Geografia, Brasília, v. 13, n. 2, p. 227-307, 2010.

CHRISTOFOLETTI, A. Geomorfologia. São Paulo: Edgard Blucher, 1974.

CHRISTOFOLETTI, A. Modelagem de Sistemas Ambientais. São Paulo: Edgard Blücher, 1999.

Conselho Nacional do Meio Ambiente - CONAMA, Resolução nº 357 de 17 de março de 2005. Dispõe Sobre a Classificação dos Corpos de Água e Diretrizes Ambientais para o seu Enquadramento.

CSJM. Plano Diretor das Bacias dos Rios Santa Maria e Jucu. Vitória, Consórcio intermunicipal para Recuperação das Bacias dos Rios Santa Maria da Vitória e Jucu, 1998.

Druck, S.; Carvalho, M.S.; Câmara, G.; Monteiro, A.V.M. (eds) "Análise Espacial de Dados Geográficos". Brasília, EMBRAPA, 2004. Disponível em: http://www.dpi.inpe.br Acesso em Março de 2017.

EMBRAPA. Sistema Brasileiro de Classificação de Solos - Rio de Janeiro: Embrapa, p. 412, 2009.

Instituto Brasileiro de Geografia e Estatística - IBGE, Censo Demográfico 2000.

Instituto Capixaba de Pesquisa, Assistência Técnica e Extensão Rural - INCAPER. Relatório 2014.

MILLER, V.C.A. Quantitative Geomorphic Study of Drainage Basin Characteristics in the Clinch Mountain Area. Virginia and Tennessee Technical Report 3, Office of Naval Research, Department of Geology, Columbia University, New York, 1953. 

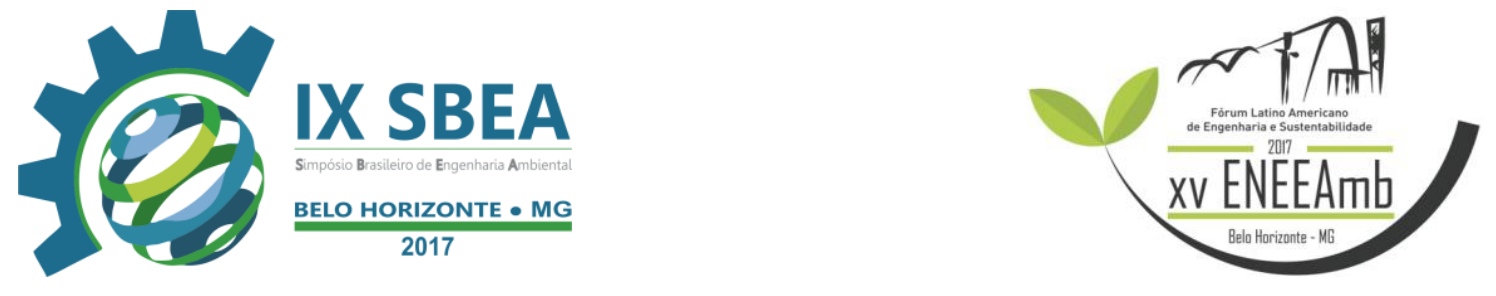

OLIVEIRA, P. T. S. et al. Caracterização morfométrica de bacias hidrográficas através de dados SRTM. Revista Brasileira de Engenharia Agrícola e Ambiental, Campina Grande, v.14, n.8, p.819-825, 2010.

SCHUMM, S. A. Evolution of drainage systems and slopes in badlands of Perth Amboy. Geological Society of America Bulletin, v.67, n.5, p.597-646, 1956

SOPRANI, J.; NASCIMENTO, G.; MARTINS, F.; PINHEIRO, C.M.; VENTURIN, S. Navegando os rios capixabas: Rio Jucu e Rio Santa Maria da Vitória. A Tribuna. Espírito Santo, 26 de ago. 2007. Suplemento Especial. 12 p.

SWAROWSKY, A. et al. Research connects soil hydrology and stream water chemistry in California oak woodlands. California Agriculture, v. 64, p. 78-84, 2010.

TUCCI, C.E.M. Hidrologia: ciência e aplicação. 2.ed. Porto Alegre: Editora da Universidade: ABRH, 1997. (Coleção ABRH de Recursos Hídricos; v.4).

USGS - Geological Survey / Serviço de Levantamento Geológico Americano. Imagens orbitais digitais gratuitas do satélite Landsat-8: data de passagem 24/04/2014. Acesso em 17 de abril de 2017. Disponível em <http://earthexplorer.usgs.gov/>. 